\title{
Distinguishing Effect of Buffing Operation on Surface Residual Stress Distribution and Susceptibility of 304L SS and 321 SS Welds to Chloride Induced SCC
}

\author{
Pandu Sunil Kumar, ${ }^{1, a, \#}, K^{2}$ Kamal Mankari, ${ }^{1, b, \#}$, Swati Ghosh Acharyya ${ }^{1, c, *}$ \\ ${ }^{1}$ School of Engineering Sciences and Technology, University of Hyderabad, India \\ asunilpandu04@gmail.com, ${ }^{b}$ mankari.kamal.1802@gmail.com \\ \# Pandu Sunil Kumar and Kamal Mankari have contributed equally to this work.
}

Keywords: Residual Stresses, Austenitic Stainless Steels, Stress Corrosion Cracking

\begin{abstract}
Stress corrosion cracking (SCC) of austenitic stainless steels (ASS) and its weldments in presence of chloride ions is a key concern in its successful application. AISI 304L SS in surface milled, turned, ground conditions have high tensile residual stresses on the surface which lead to early cracking in an aggressive environment. Spot welds of AISI 321 SS have shown multiple failures due to chloride induced SCC as a result of high magnitude of tensile residual stresses and improper post weld heat treatment. The present study proposes a simple surface engineering method to prevent the initiation of stress corrosion cracking in austenitic stainless steel and its welds in presence of chloride ions. 304L SS in milled, turned and ground conditions and 321 SS in spot welded condition was subjected to surface buffing operation. Surface roughness was calculated using a surface profilometer and residual stresses were determined. Residual stress distribution, and phase transformation were calculated using X-ray diffraction measurements. The detailed microstructural characterization was performed using field emission scanning electron microscopy (FESEM). 304L plates and 321 SS welds in buffed and un-buffed conditions were tested for SCC susceptibility by exposing these to boiling $\mathrm{MgCl}_{2}$ as per ASTM G36. Results showed that 304L SS and 321 SS were resistant to SCC in buffed conditions as no cracking occured even after prolnged exposure to boiling $\mathrm{MgCl}_{2}$. Buffing being a very simple, economic and portable operation can be easily applied on large components of AISI 304L SS after the conventional surface finishing operations and AISI 321 SS weld also can be extended to components in service in an aggressive environment.
\end{abstract}

\section{Introduction}

Austenitic stainless steels have good corrosion resistance and mechanical properties. However, these become highly susceptible to SCC when subjected to different surface finishing and welding operations [1-3]. Laser peening and shot peening are generally used for enhancing SCC resistance, but these processes induce plastic strain in the material and are not economic. Hence a simple and economic route is essential in preventing SCC. We have shown in our previous report that simple surface buffing can be used to enhance the SCC resistance of austenitic stainless steels [4]. The present study substantiates the effectiveness of buffing in preventing the initiation of $\mathrm{Cl}^{-}$induced SCC of austenitic stainless steel in presence of chloride ions. 304L SS in milled, turned and ground conditions and 321 SS in spot welded condition when subjected to surface buffing operation. 


\section{Experimental \\ Materials and methods}

In the present study two steels namely, AISI 304L SS (C 0.03, Cr 18, Ni 8, Mn 1.6, P 0.04, Si $0.4, \mathrm{~S} 0.03$, balance Fe) wt \%, and AISI 321 SS welds (C 0.024, Cr 17.41, Ni 9.14, Mn 1.64, Ti 0.23, Mo 0.37, P 0.04, Si 0.4, S 0.03) wt\% were used. AISI 304L SS samples were cut into a dimension of $100 \mathrm{~mm} \mathrm{X} 25 \mathrm{~mm} \mathrm{X} 5 \mathrm{~mm}$ plates and they were solution annealed in order to remove the internal stresses present in the material. AISI 304 L SS was subjected to three different surface working conditions namely a) milling b) turning and c) grinding operations at a feed rate of $0.1 \mathrm{~mm} / \mathrm{rev}$ to remove $0.5 \mathrm{~mm}$ from the surface [7]. Subsequently, the samples were

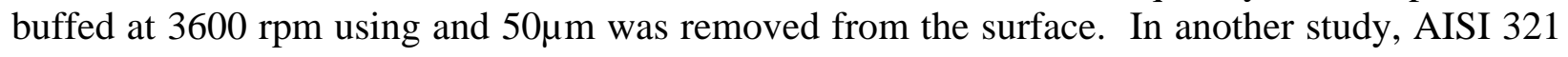
SS tubes having $72 \mathrm{~mm}$ diameter, $3 \mathrm{~mm}$ thickness and length of $3.6 \mathrm{~m}$ having spot welds on the surface were subjected to buffing and 50 $\mathrm{mm}$ was removed. Both the samples were tested for SCC susceptibility in buffed and unbuffed condition. During buffing compressive forces are applied on the sample substrate as shown in the schematic given below (Figure 1). The buffing wheel is rotated at a set speed and is rastered on the surface of the workpiece imparting compressive

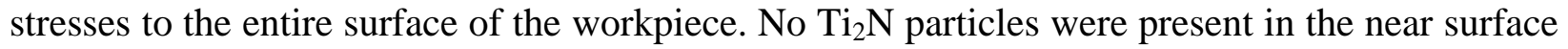
region of buffed samples in each case.
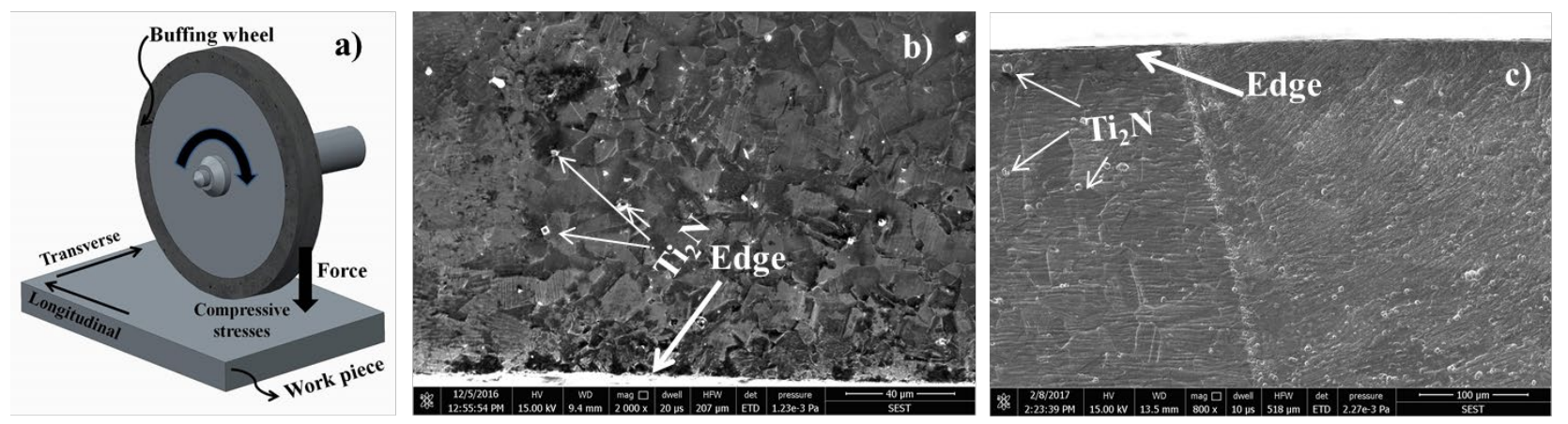

Fig 1: a) Schematic of the buffing operation b) cross sectional micrograph of 321 SS in buffed condition and c) cross sectional micrograph of 321 SS in un-buffed condition.

\section{Surface roughness measurements}

Surface roughness measurements were done on all samples using a surface profilometer (contact mode) with a scan length of $1 \mu \mathrm{m}$ at a scan speed of $0.01 \mathrm{~mm} / \mathrm{sec}$ with a minimum resolution step of $1 \mathrm{~nm}$. $321 \mathrm{SS}$ ring samples were measured using an optical surface profilometer (non contact mode) with a scan length of $1 \mathrm{~mm}$ at a scan speed of $47 \mu \mathrm{m} / \mathrm{sec}$ with a resolution of $0.2 \mathrm{~nm}$. The average roughness $(\mathrm{Ra})$ was determined in each case.

\section{XRD phase analysis}

XRD studies were conducted on all the samples to confirm the phases present in the material using BRUKER G8 powder XRD, $\mathrm{Cu}-\mathrm{K} \alpha$ source, $\lambda=1.54 \AA$, Bragg angle, $2 \theta$ from $\left(30-100^{\circ}\right)$, step size 0.01 and step/scan 0.5 at an accelerating voltage of $40 \mathrm{kV}$ and $30 \mathrm{~A}$.

\section{Residual stress measurements}

Residual stresses measurements were conducted on X- stress G2R (High-resolution XRD) to find the surface residual stresses present in the material. By using $\mathrm{Cr}-\mathrm{K} \alpha$ source, applied voltage 27 $\mathrm{kV}$, a current of $70 \mathrm{~mA}, \lambda=2.28$, Bragg angle $147.6^{\circ}$ was kept constant for all the samples, (hkl 311) peak was considered for diffraction with a step size of $0.1^{\circ}$ [5]. Collimeter diameter $4 \mathrm{~mm}$ and exposure time of $20 \mathrm{~s}$ was used. The multiexposure side inclination and fixed $(\chi)$ chi method was adopted, at $0^{\circ}$ and $90^{\circ}$ for each measurement. 2D stress state was assumed $\sin ^{2} \chi$ technique was applied for residual stress analysis. 


\section{Determination of SCC resistance}

The SCC susceptibility of AISI 304L SS and AISI 321 SS in buffed and un-buffed condition was determined using ASTM G 36 [6] in surface worked and welded conditions respectively. SCC test was conducted for $3 \mathrm{~h}$ and $9 \mathrm{~h}$ in AISI 304L SS samples and $5 \mathrm{~h}$ and $10 \mathrm{~h}$ in AISI $321 \mathrm{SS}$ samples. As per ASTM G 36, $600 \mathrm{~g}$ of magnesium chloride hexahydrate $\left(\mathrm{MgCl}_{2} \cdot 6 \mathrm{H}_{2} \mathrm{O}\right)$ was melted and test temperature was maintained at $155 \pm 1^{\circ} \mathrm{C}$ throughout the test. Care has been taken to prevent vapor losses

\section{Results and Discussion}

\section{Surface roughness measurements:}

Surface roughness values ( $\mathrm{Ra}$ ) for different surface working conditions have been tabulated in Table1. In both 304L SS and 321 SS surface roughness in buffed conditions was much less as compared to un-buffed conditions. Higher the surface roughness, greater the tendency to form localized pockets of high chloride concentration and early initiation of SCC.

Table 1: Average surface roughness values of 304L SS and 321 SS in un-buffed and buffed conditions

\begin{tabular}{|c|c|c|}
\hline Material & Material conditions & $\begin{array}{c}\text { Surface roughness (Ra) } \\
\text { in } \mathbf{~} \mathbf{m}\end{array}$ \\
\hline \multirow{3}{*}{ 304L SS } & Milled & $2.1 \pm 0.15$ \\
\cline { 2 - 3 } & Turned & $4.3 \pm 0.30$ \\
\cline { 2 - 3 } & Ground & $0.6 \pm 0.04$ \\
\cline { 2 - 3 } & Milled + Buffed & $0.13 \pm 0.06$ \\
\cline { 2 - 3 } & Turned + Buffed & $0.11 \pm 0.04$ \\
\cline { 2 - 3 } & Ground + Buffed & $0.08 \pm 0.02$ \\
\hline \multirow{5}{*}{321 SS } & Spot welded & $1.74 \pm 0.24$ \\
\cline { 2 - 3 } & Spot welded +Buffed & $0.94 \pm 0.12$ \\
\hline
\end{tabular}

\section{XRD studies}

Figure 2 shows the XRD spectra of 304L SS under different surface working conditions. Solution annealed sample showed austenitic $(\gamma)$ phase and other surface worked samples showed strain-induced martensite $\left(\alpha^{\prime}\right)$ phase due to the metastable nature of austenitic stainless steel.

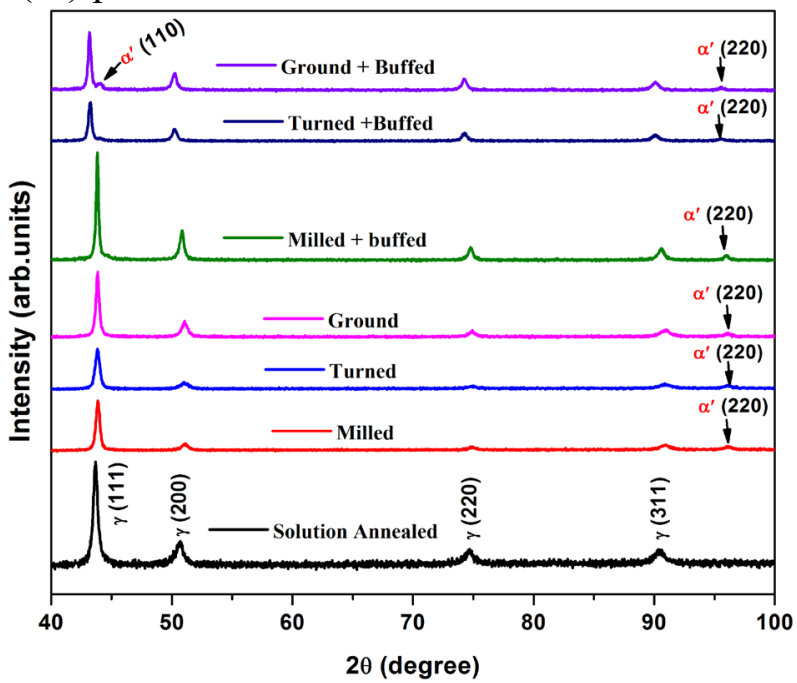

Fig. 2: Shows the XRD spectra of 304L SS in different surface working conditions.

Figure 3 shows the XRD spectra of the spot welded region of 321 SS in both buffed and unbuffed condition. Characteristic austenitic peaks were observed in both the cases together with the presence of stress induced martensite. The number of peaks for stress induced martensite was 
much higher for buffed condition. The $\mathrm{Ti}_{2} \mathrm{~N}$ present in the surface layers of 321SS gets removed on buffing. Optical microstructures support the observation.

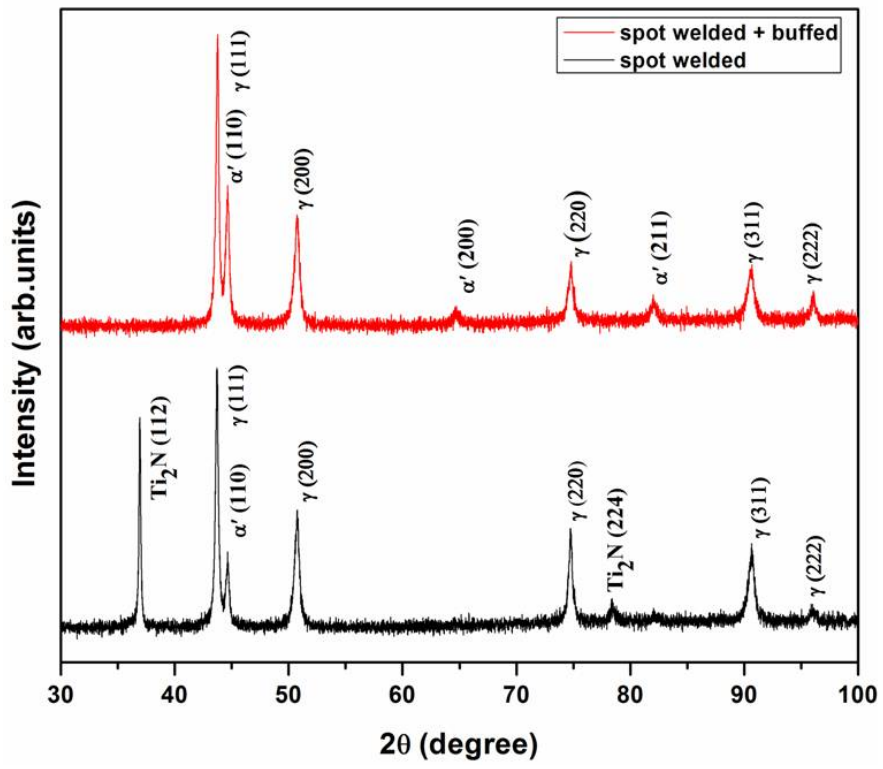

Fig. 3: Shows the XRD spectra of 321 SS in spot welded and spot welded followed by a buffed condition

\section{Residual stress measurements}

Table 2 gives the residual stresses of 304L SS and 321 SS under different conditions. The measurements were taken in longitudinal and transverse direction. The result shows that for 304L SS in milled, turned and ground conditions have high magnitude of tensile residual stresses. A similar result has been reported in earlier studies performed by some of the authors [7-8]. However, compressive residual stresses were found to be present on the surfaces in buffed condition. Similarly, the HAZ and the fusion zone of spot welds of 321 SS were found to have tensile residual stresses in un-buffed condition and compressive residual stresses in buffed condition.

Table 2: residual stress values of 304L SS and 321 SS in different conditions

\begin{tabular}{|c|c|c|}
\hline 304L SS conditions & $\mathbf{0}^{\circ} \mathbf{~ M P a )}$ & $\mathbf{9 0}^{\circ} \mathbf{~ M P a )}$ \\
\hline Milled & $740 \pm 86$ & $639 \pm 71$ \\
\hline Turned & $397 \pm 82$ & $69 \pm 85$ \\
\hline Ground & $192 \pm 40$ & $15 \pm 39$ \\
\hline Milled + Buffed & $-386 \pm 21$ & $-378 \pm 16$ \\
\hline Turned + Buffed & $-523 \pm 17$ & $-504 \pm 26$ \\
\hline Ground + Buffed & $-481 \pm 22$ & $-409 \pm 16$ \\
\hline 321 SS conditions & $\left.\mathbf{0}^{\mathbf{0}} \mathbf{M P a}\right)$ & $\left.\mathbf{9 0}^{\circ} \mathbf{M P a}\right)$ \\
\hline Base material & $-239 \pm 23$ & $-306 \pm 57$ \\
\hline Spot + buffed & $-351 \pm 17$ & $-433 \pm 24$ \\
\hline
\end{tabular}

\section{Determination of susceptibility to stress corrosion cracking (SCC)}

Figure 4 and Figure 5 shows the FESEM surface micrographs of 304L SS in a) milled b) turned c) ground before and after buffing after exposure to $3 \mathrm{~h}$ and $9 \mathrm{~h}$ of SCC test respectively. The results showed that the samples in milled ground and turned condition were highly susceptible to SCC, whereas the samples in buffed condition after $3 \mathrm{~h}$ and $9 \mathrm{~h}$ of exposure. Pit initiation was observed in some cases after $9 \mathrm{~h}$ of exposure due to the preferential dissolution of martensite on the surface. 


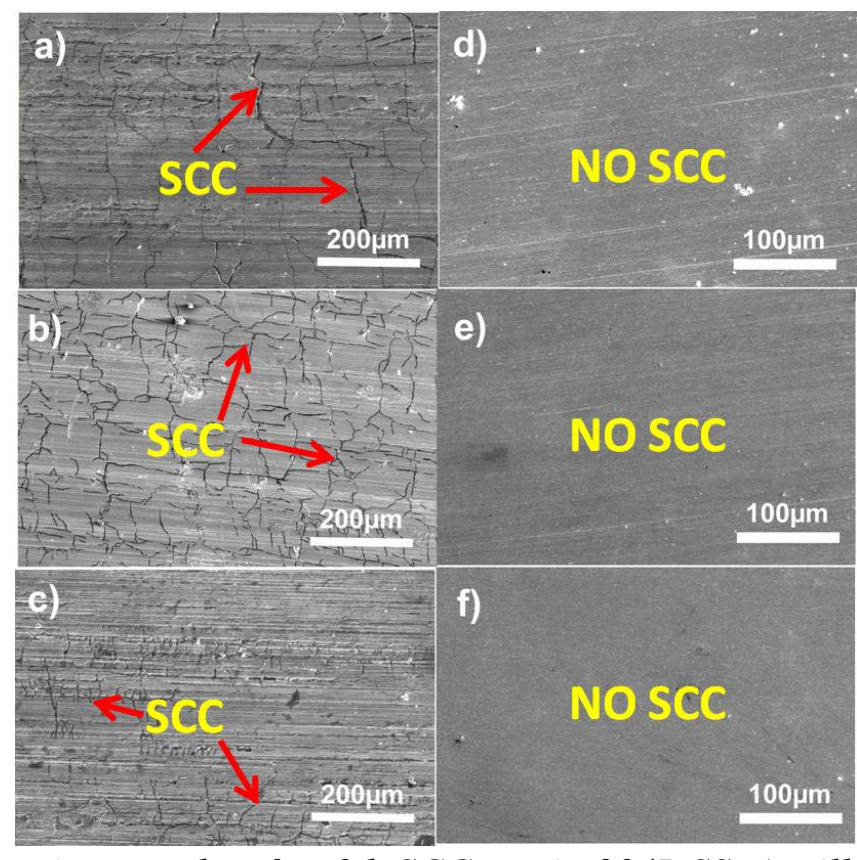

Fig. 4: Shows surface micrographs after 3 h SCC test in 304L SS a) milled b) turned c) ground d) milled and buffed e) turned and buffed f) ground and buffed.
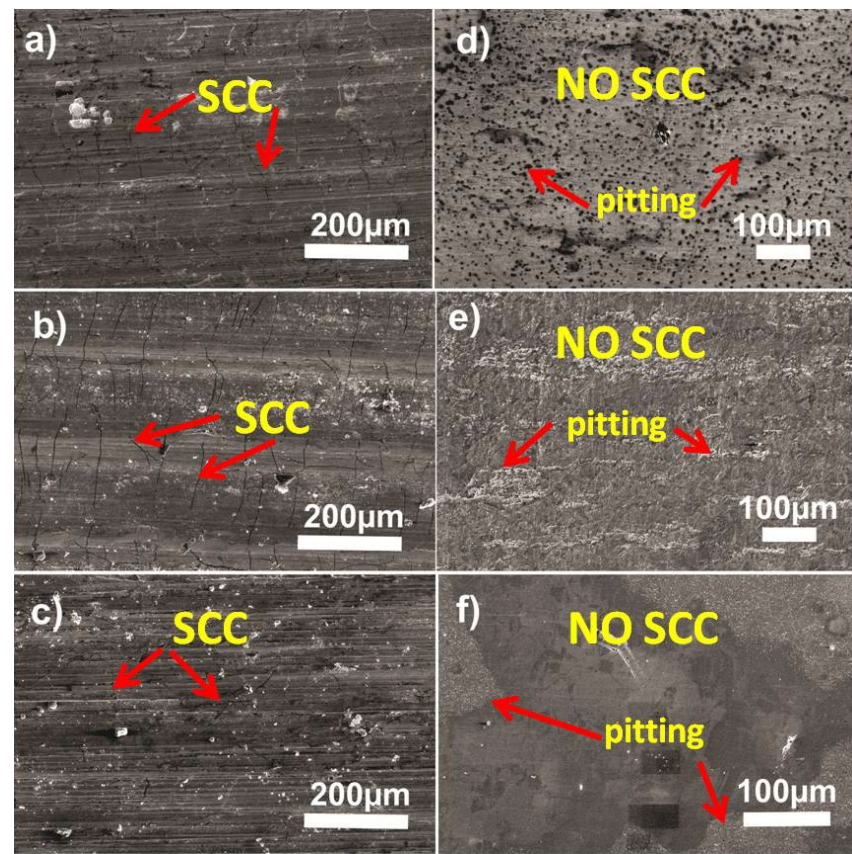

pitting

$100 \mathrm{um}$

Fig. 5: Shows surface micrographs after 9 h SCC test in 304L SS a) milled b) turned c) ground d) milled and buffed e) turned and buffed $f$ ) ground and buffed conditions.

Figure 6 shows the FESEM micrographs of 321 SS spot welded region after exposure to boiling $\mathrm{MgCl}_{2}$ for a) $5 \mathrm{~h}$ and b) $10 \mathrm{~h}$. Figure 6(c-d) shows spot welded and buffed samples after 5 $\mathrm{h}$ and $10 \mathrm{~h}$ test respectively. High densities of cracks were observed in un-buffed condition whereas no cracking was observed in buffed samples. 


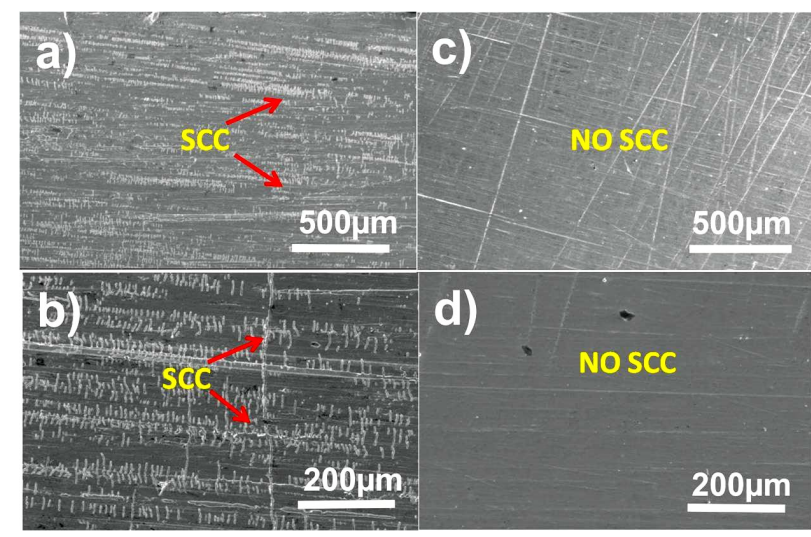

Fig. 6: Shows surface micrographs of 321 SS in spot weld condition after 5 h and $10 \mathrm{~h}$ SCC test respectively ( $a-b)$ before buffing and $(c-d)$ after buffed condition.

\section{Summary}

The effect of buffing operation on the SCC susceptibility of austenitic stainless steel grade AISI 304L and 321 spot welds was established. Buffing enhances the SCC resistance of austenitic stainless steel by converting the tensile residual stresses present on the surface of machined and welded stainless steel to compressive residual stresses together with reduction in surface roughness and removal of the plastic strain near the surface formed as a result of machining.

\section{References}

[1] N. Zhou, R. Pettersson, R. Lin Peng, M. Schönning, Effect of surface grinding on chloride induced SCC of 304L, Mater. Sci. Eng. A, 658 (2016) 50-59.

https://doi.org/10.1016/j.msea.2016.01.078

[2] J.Ł.S. Topolska, M. Głowacka, Failure of austenitic stainless steel tubes during steam generator operation, J. Achiev. Mater. Manuf. Eng. 55 (2012) 378-385.

[3] S. Ghosh, V. Kain, Microstructural changes in AISI 304L stainless steel due to surface machining: Effect on its susceptibility to chloride stress corrosion cracking, J. Nucl. Mater., 403 (2010) 62-67. https://doi.org/10.1016/j.jnucmat.2010.05.028

[4] Pandu Sunil Kumar, Swati Ghosh Acharyya, S.V. Ramana Rao, Komal Kapoor, Surface buffing and its effect on chloride induced SCC of 304L austenitic stainless steel, 2018 IOP Conf. Ser.: Mater. Sci. Eng. 314 012002, doi:10.1088/1757899X/314/1/012002.

[5] H.B. P. Withers, Residual stress. Part 1 - measurement techniques., Mater. Sci. Tech., 17 (2001) 355-365. https://doi.org/10.1179/026708301101509980

[6] ASTM G-36, Standard Practice for Evaluating Stress-Corrosion-Cracking Resistance of Metals and Alloys in a Boiling Magnesium Chloride Solution, 2006, Reapproved

[7] S. Ghosh, V. Kain, Effect of surface machining and cold working on the ambient temperature chloride stress corrosion cracking susceptibility of AISI 304L stainless steel, Mater. Sci. Eng. A 527 (3) (2010) 679-683. https://doi.org/10.1016/j.msea.2009.08.039

[8] S. Ghosh, V.P.S. Rana, V. Kain, V. Mittal, S.K. Baveja, Role of residual stresses induced by industrial fabrication on stress corrosion cracking susceptibility of austenitic stainless steel, Mater. Des. 32 (7) (2011) 3823-3831. https://doi.org/10.1016/j.matdes.2011.03.012 